\title{
Sentential Particles and Clausal Typing in the Veneto Dialects
}

\author{
Nicola Munaro \& Cecilia Poletto \\ University of Venice, ISTC-CNR Padua \\ munaro@unive.it cecilia.poletto@unipd.it
}

\begin{abstract}
In this work we examine several sentential particles, occurring in imperatives, main exclamative and interrogative sentences, which display a uniform syntactic behaviour. We analyse them as heads of high CP projections which require their specifier to be filled either by the $w h$-item (in sentences where there is one) or by the whole clause, yielding the sentence final position of the particle. The hypothesis that they are $\mathrm{C}^{\circ}$-heads accounts for their sensitivity to sentence type and for their occurrence only in matrix contexts. We also provide a first sketch of their semantic contribution, showing that they select "non standard' contexts and interact with tense and modality of the verb when the whole $\mathrm{CP}$ has moved to their specifier.
\end{abstract}

\section{Introduction}

In this work we describe and analyse both the syntactic and the semantic properties of a number of sentential particles (henceforth $S P S$ ), which can appear in some Veneto dialects in main non declarative clauses. ${ }^{1}$

The presence of these particles induces interesting interpretive effects; more generally, an investigation of their properties is relevant for the analysis of the left periphery of the clause; in addition, a detailed study of these particles turns out to have theoretical relevance for a cross-linguistic theory of clausal typing on the one hand and for a deeper understanding of the syntaxsemantics interface on the other. The distribution of SPS also involves a number of interpretive and pragmatic distinctions that contribute to highlight the way sentence type is encoded in the syntactic structure and to provide

\footnotetext{
${ }^{1}$ The content of this article has been presented at the XXIX IGG meeting in Urbino (13-15 February 2003); we thank that audience as well as Paola Benincà, Guglielmo Cinque, Alessandra Giorgi, Hans Obenauer for helpful comments and suggestions; special thanks go to Paul Portner and Raffaella Zanuttini for patiently discussing some of the semantic aspects of the issue addressed in section 5; needless to say, the responsibility for any mistakes rests entirely on us. This paper develops and elaborates some aspects of Munaro \& Poletto 2002, (forthcoming; although the paper is the product of a constant collaboration of the two authors, for the concerns of the Italian academy Nicola Munaro takes responsibility for sections 1-3 and Cecilia Poletto for sections 4-6.
} 
some insights into more fine-grained distinctions internal to each sentence type.

We will systematically analyse data from two varieties, a Northern Veneto variety and an Eastern Veneto variety (Pagotto and Venetian, glossed as Pg and $V e$ respectively); however, the particles described here occur, with a partially different distribution, in several other dialects of the North-Eastern Italian area, which we will occasionally refer to as well.

While SPS can appear in main interrogatives, exclamatives or imperatives, none of them can occur in declarative clauses or in embedded contexts; furthermore, they always occur in 'special' contexts, in the sense that they induce a presupposition in the clause determined either by the linguistic context or by the universe of the discourse.

The particles we consider also share the following distributional property: they can occur in sentence final position, a fact that - we claim - can be derived by movement of the whole CP to the specifier position of the head occupied by the particle, as illustrated in (1):

$$
\text { (1) }\left[\mathrm{Spec}, p r t \mathrm{CP}_{\mathrm{i}}[p r t]\left[\mathrm{t}_{\mathrm{i}}\right]\right]
$$

Beside the sentence final occurrence, some particles can also occur either immediately after the $w h$-element or with a $w h$-item in isolation.

This is the outline of the article: in section 2, we address the issue of the categorial status of the particles, providing some arguments in favour of the hypothesis that SPS are heads; in section 3, we provide a description of the syntactic properties shared by all $S P S$; in section 4 , we analyse in detail the syntactic derivation exploiting clause preposing; in section 5, we examine more closely the interpretive properties and attempt a description of the semantic contribution of each particle; and in section 6 , we provide a summary of the article.

\section{Sentential Particles as $\mathrm{X}^{\circ}$ Categories}

A priori, $S P s$ can be analysed either as heads or as specifiers. The head status of the SPS is suggested by the fact that they cannot be modified or focalized:
a. *Cossa gali
fato, proprio ti?!
$\mathrm{Ve}$ what have-they done,just ti
b. *Zeli partii, proprio po?
$\mathrm{Ve}$ have-they left, just po
c. *Quando riveli, proprio mo?! when arrive-they,just mo


d. *L'é fret incoi, proprio lu! it-is cold today,just lu

(3) a. *Cossa gali fato, TI?!

what have-they done TI

b. *Quando riveli, MO?! when arrive-they $M O$

Pg

c. *Eli partidi, $\mathrm{PO}$ ? have-they left $P O$

d. *L'é fret incoi, LU! it-is cold today $L U$

The ungrammaticality of (2) and (3) and the fact that $S P S$ cannot be used in isolation would be completely unexpected if $S P S$ were located in some specifier position. $^{2}$

Evidence for the head status of $S P S$ is also provided by their diachronic evolution: two of these particles, namely $t i$ and $l u$, were originally tonic pronouns, the second singular and third singular masculine forms, respectively; however, they have a different distribution with respect to subject pronouns.

The particle $t i$ is compatible with third person subjects and can cooccur with the homophonous tonic pronominal subject $t i$ :

(4) a. Dove zelo ndà, tî? where has-he gone, $t i$

b. Ti, dove ti ze 'ndà, ti? $\mathrm{Ve}$ you, where you-have gone, $t i$

The particle $l u$ is compatible with singular or plural third person subjects (though not with first and second person subjects): ${ }^{3}$

${ }^{2}$ Another possible analysis is that $S P S$ are merged in a low specifier position of the IP field and are subsequently raised to some specifier of the CP layer. Notice, however, that this option should be discarded in view of the impossibility for the SPS to undergo any kind of modification.

${ }^{3}$ Notice however that a preverbal subject is compatible with $l u$ only if it is $3^{\text {rd }}$ person singular:

(i) a. Al to amigo l'é rivà, lu your friend he-has arrived, lu

b. I to amighi i é rivadi, lori/*lu your friends they-have arrived, they/lu

Furthermore, $l u$ is generally compatible with postverbal subjects and induces a contrastive focalization of the subject with any verb class: 
(5) a. L'é rivà al to amigo, lu

$\operatorname{Pg}$ it-has arrived your friend, lu

b. L'é riva i to amighi, lu

$\mathrm{Pg}$ it-has arrived your friends, lu

(6) a. *Son vegnest anca mi, lu

$\mathrm{Pg}$ have come also $I, \quad l u$

b. *Te sé rivà anca ti, lu you-have arrived also you,lu

c. * Sion partidi anca noi, lu have left also we, lu

Moreover, while the particle $l u$ is restricted to third person subject clauses in Pagotto, this restriction does not hold in Paduan, where, as discussed in Benincà 1996) $l u$ may appear in exclamatives and is compatible with first, second and third person subjects: ${ }^{4}$
a. A ghe go dito tuto
a me sorèla, mi,lu!
A cl-dat-have told everything to my sister, I, lu
b. A te ghe fato ben, ti, lu!
A you-have done well, you,lu
c. A le gera vignù trovarte, le toze, $\quad l u !$
A they-had come see you, your daughters, lu

Paduan

On the basis of these data, $t i$ and $l u$ cannot be analysed as personal pronouns, although the diachronic connection is clearly witnessed by the homophony of the two forms.

As for the other two particles, mo and po, they were most probably temporal adverbs in origin, po being connected to Latin post ('afterwards', see Pellegrini 1972) and mo to Latin quomodo ('now', see, among others Rohlfs

(ii) a. L'à magnà tut al tozatel, lu. he-has eaten everything the child, lu

b. L'à laorà to fradel, lu, incoi. he-has worked your brother, lu, today

(iii) L'é rivà (anca/proprio) to fradel, lu. he-has arrived (also/just) your brother, lu

The non-contrastive interpretation is possible only with right-dislocation of the subject:

(iv) L'é rivà, lu, to fradel (atu vist?) he-has arrived, lu, your brother (have-you seen?)

${ }^{4}$ Moreover, $l u$ is compatible with adjectival predicates with a feminine ending:

(i) L'é vera, (lu), che i é tornadi, it-is true (lu) that they-have come back (lu) 
1969); mo does in fact still retain the original temporal meaning in the Central and Southern Italian dialects).

Based on this evidence, we propose that SPS are the result of a grammaticalization process which includes a phonological as well as a semantic impoverishment along with the development of special syntactic properties; such a process is generally attested in the case of elements becoming the overt realization of (marked values of) functional heads, and not with specifiers. Hence, we propose to analyse the SPS considered here as filling functional heads located in a layered CP field (see Rizzi 1997).

\section{Common Syntactic Properties}

It should be pointed out first that the SPS considered here behave differently from other particles attested in the Veneto dialects as well as in other Northern Italian dialects, which are characterized by two properties not shared by the particles we have examined: they occur in initial position and have no presuppositional import. This is the case of the particle $e$ in the Southern Veneto dialect of Taglio di Po, which marks the exclamative illocutionary force of the utterance in which it occurs; as shown by (8) and (9), in this variety an exclamative clause is fully grammatical only if the particle $e$ appears in sentence initial position:

(8) a. E c bel libro c l'à scrito! Taglio di Po

b. ${ }^{*} C($ he) bel libro c l'à scrito $e$ ! [E] what a nice book that he-has written [e]

(9) a. *Che bel libro c l'à scrito!

Taglio di Po What a nice book that he-has written

b. ${ }^{*}$ Co beo! ${ }^{5}$ How nice

We suggest that particles like $e$ have a purely typing function and consequently are obligatory in the clause type they mark. This is not the case for our $S P s$, which seem at first sight optional, although, as we claim, they convey a special meaning.

As mentioned above, the SPS attested in the two dialects examined here share the following distributional properties:

\footnotetext{
${ }^{5}$ The element $c o$ is used only in exclamative clauses and can exclusively modify adjectives.
} 
(10) a. SPs can occur in sentence final position;

b. those SPS which can occur immediately after the wh-element, can also cooccur with the $w h$-item in isolation;

c. SPS are sensitive to the clause type: they cannot occur in declarative clauses;

d. SPS never occur in embedded contexts;

e. SPS can/must be followed by right dislocated arguments.

With respect to the first property, the sentence final position is always available for the particle, independently of the clause type it is associated with.

As shown by the following examples, the particle $t i$ occurs exclusively in main $w h$-questions, and the only possible position is the sentence final one:

(11) a. Dove valo, ti?

b. *Ti, dove valo?

[Ti] where goes-he [ti]

(12) a. Dove zelo ndà, ti?

$\mathrm{Ve}$

b. *Dove zelo, ti, ndà? where has-he [ti] gone [ti]

The particle mo, which can appear both in imperative and in interrogative clauses, can always appear in sentence final position but never in sentenceinitial position, as witnessed by the following contrasts:

(13) a. Parècia sta minestra, mo!

b. *Mo parècia sta minestra!

[Mo] prepare this soup [mo]

(14) a. Vien qua, mo!

$\mathrm{Ve}$

b. *Mo, vien qua!

[Mo] comehere [mo]

(15) a. Ali magnà, mo?

$\mathrm{Pg}$

b. *Mo, ali magnà?

[Mo] have-they eaten [mo]

(16) a. Quando rivelo, mo?

b. *Mo, quando rivelo?

[Mo] when arrives-he [mo]

The sentence-final occurrence is also attested with the particles $p o$ and $l u$, appearing in interrogative and exclamative contexts, respectively: 
(17) a. Quando eli rivadi, po? when have-they arrived po

b. Eli partidi, po? have-they left po

(18) a. Dove zei ndai po?

where have-they gone po

b. Zei ndai via, po?

have-they gone away po

(19) a. L'à piovest, lu!

b. $\quad(* \mathrm{Lu})$ l'à $(* \mathrm{lu})$ piovest! [Lu] ithas [lu] rained [lu]

Secondly, among those $S P s$ that occur in wh-contexts, some can also occur immediately after the $w h$-item and with a $w h$-item in isolation. This is the case for the particles $m o$ and $p o$ in Pagotto, as exemplified in (20)-(23), but not for $t i$, for example, as illustrated in (24): ${ }^{6}$

(20) a. Quando rivaràli, mo?

b. Quando, mo, rivaràli? when [mo] arrive-fut-they [mo]

${ }^{6}$ As discussed in Munaro 1997, Pagotto belongs to the group of Northern Italian dialects in which some classes of $w h$-items can appear either sentence-initially or sentence-internally in main $w h$-questions; however, the position of the $w h$-item does not interact in a relevant way with the presence of the particle.

With respect to the particle $p o$, the wh-element parché displays a special behaviour, as in Pagotto the position after the $w h$-item is preferred to the sentence-final one:

(i) a. Parché po éli 'ndadi via?

b. ?Parché éli 'ndadi via, po?

c. ?Po, parché eli 'ndadi via?

[Po] why [po] have-they gone away [po]

As shown by (ic), the sentence initial position of po is not excluded in Pagotto; we leave a more detailed investigation of this fact for future research.

In Venetian parche is the only wh-item that can be immediately followed by $p o$ and be used in isolation with the particle, as shown by the data in (ii):

(ii) a. *Dove, po, zei ndai?

where po have-they gone

b. Parché, po, i ze/zeli ndai via?

c. Parché po? why [po] (they-have/have-they gone away) 
(21) a. Che mo?

what mo

b. Andé mo?

where mo

(22) a. Quando eli rivadi, po?

$\mathrm{Pg}$

b. Quando, po, eli rivadi?

when [po] have-they arrived [po]

(23) a. Andé po?

where po

b. Quando po?

$\mathrm{Pg}$ when po

(24) a. *Dove, ti, zelo ndà?

Ve

b. *Dove ti where [ti] has-he gone

Thirdly, all SPS are sensitive to clause type: the examples reported above show that $S P S$ always occur in interrogative, exclamative or imperative clauses and are never found in declarative clauses. In addition, they always convey a presuppositional entailment which we try to describe in greater detail below.

Finally, the occurrence of SPS is restricted to main contexts. As shown by the following data, particles are banned from embedded clauses, independently of the clause type they are associated with:

(25) a. El me ga domandà dove (*ti) che i ze ndai (*ti) Ve he-me-hasasked where [ti] that they-have gone [ti]

b. No so dirte quando(*ti) che i é partidi (*ti) Pg I can't tell you when [ti] that they-have left [ti]

(26) a. I me a domandà cossa (*mo) che avon fat (*mo) Pg they-haveasked me what [mo] that we have done [mo]

b. No so andé (*mo) che i é $\quad \mathrm{Pg}$ I don't know where [mo] that they-have gone [mo]

(27) a. I me à domandà parché $\left({ }^{*}\right.$ po) che l'à parlà (*po) $\mathrm{Pg}$ they-me-have asked why [po] thathe-has spoken [po]

b. No so dove (*po) che el ze ndà (*po) Ve I don't know where [po] that he-has gone [po] 


$$
\begin{aligned}
& \text { L'à dit } \quad\left({ }^{*} l u\right) \text { che l'à piovest }(* 1 \mathrm{u}) \text {, ieri } \quad \text { sera }(* 1 \mathrm{u})^{7} \quad \text { Pg } \\
& \text { he-has said }[l u] \text { that it-has rained } \quad[l u] \text { yesterdayevening }[l u]
\end{aligned}
$$

The distributional constraint on main clauses suggests that the presence of the particle entails the activation of (some portion of) the CP-layer, where the main versus embedded distinction is encoded (see Rizzi 1997, among others); we address this issue more thoroughly in the next section. ${ }^{8}$

${ }^{7}$ Notice that $l u$ is compatible with a subjective clause, that can be either preceded or followed by the particle:

(i) a. L'é meio, lu, che te vegne ale nove

b. L'é meio che te vegne ale nove, lu it is better [lu] that you-come at nine $[l u]$

(ii) a. L'é bel, lu, sveiarse tardi ala matina

b. L'é bel sveiarse tardi ala matina, lu it is nice [lu] to wake up late in the morning [lu]

Incidentally, these data provide evidence that $l u$ is not a tonic pronoun in these contexts.

${ }^{8}$ A further common distributional feature concerns the fact that all SPS are incompatible with sentential negation, as shown by the Venetian imperative in (i) and the Pagotto interrogatives and exclamatives in (ii) and (iii):

(i) *No sta farlo, mo! don't do it, mo

(ii) a. *Andé no i é/éli ndadi, ti? where not they-have/have-they gone, $t i$

b. *No i a/ali fat che, mo? not they-have/have-they done what, mo

(iii) a. *No l'à piovest, lu not it-has rained, lu

b. *No l'é rivà (lu) nisuni, (lu) not it-has arrived (lu) anybody (lu)

The Pagotto examples in (iv) might suggest that the particle mo is indeed compatible with negation in yes/no questions:

(iv) a. No i gnen, mo?

not they-come, mo

b. No te dis gnent, mo?

not you-say anything, mo

However, as discussed by several authors (see, among others, Portner \& Zanuttini 1998) negation in yes/no questions is an instance of so-called expletive negation, which has only a presuppositional value, and does not perform the function of a real negative marker; as a consequence, the generalization that all the SPS we consider are incompatible with real sentential negation holds; for the time being, we do not have an explanation for this fact and leave a deeper investigation of this issue for future research. 
Notice furthermore that arguments are generally right-dislocated (as witnessed by the presence of resumptive clitics) in interrogative clauses containing a particle:

(29) a. Dove le gavarò messe, ti, le ciave?! where cl-acc have-fut-I put where, ti, the keys

$\mathrm{Ve}$

b. Quando lo àla magnà, mo, al polastro?! when cl-acc has-she eaten, mo, the chicken

However, this effect is not due to the presence of the particle, but is a general property of main wh-questions (see Antinucci \& Cinque 1977 and Munaro, Poletto \& Pollock 2001 for further discussion of this issue).

This effect, in fact, is not attested in imperative clauses, where an object DP or an embedded clause can either occur in its canonical position or be right dislocated after the particle:

(30) a. Magna sta minestra, mo! $\mathrm{Ve} / \mathrm{Pg}$

b. Magna, mo, sta minestra! $\mathrm{Ve}$

c. Magnela, mo, sta minestra! eat (cl) [mo] this soup [mo]

(31) a. Gnen qua che finison sto laoro, mo!

b. Gnen qua, mo, che finison sto laoro! come here [mo] that we finish this work [mo]

(32) a. Vien che fazemo sta roba, mo!

b. Vien mo, che fazemo sta roba! come [mo] that we do this thing [mo]

In the case of the particle $l u$, which occurs in yes/no exclamatives, adverbials are also preferably right-dislocated:

(33) a. L'à piovest, lu, ieri sera

b.??L'à piovest ieri sera, lu it has rained [lu] last night [lu]

(34) a. L'é fret, lu, qua dentro

b. ?L'é fret, qua dentro, lu it is cold [lu] inside here [lu]

In the next section, we will analyse all the syntactic properties listed here, trying to provide a plausible unified account for all of them. 


\section{Clause Fronting to [Spec,Prt]}

We propose to account for the fact that all $S P S$ can occur in sentence-final position under the assumption that $S P S$ are located in a head position of the $\mathrm{CP}$ layer and that their sentence final position is derived via movement of their clausal complement, the whole $\mathrm{CP}$, to their specifier, as illustrated in (35):

$$
\left[{ }_{\mathrm{FP}} \mathrm{CP}_{\mathrm{i}}\left[\mathrm{F}^{\circ} \text { particle }\right]\left[\mathrm{CP}_{\mathrm{i}} \mathrm{t}_{1}\right]\right.
$$

The hypothesis that $S P S$ are located very high in the structure and that the whole CP must raise across them might seem at first sight a rather ad hoc proposal. We will therefore compare this analysis with the null hypothesis, namely with the view that $S P S$ are located in the low position inside the IP field, showing that the null hypothesis encounters a number of problems; in addition, there are empirical arguments suggesting that these particles belong to the CP-layer.

Firstly, we have to exclude the possibility that $S P S$ are merged inside the VP, as they have no argument status. The assumption that $S P s$ are located very low in the IP field would force us to the problematic conclusion that, given their sentence final positioning, all arguments must have vacated the VP; if this analysis might in principle be conceivable for object DPs (which move out of the VP in order to get case in some agreement projection), it looks much less plausible for PPs, which, not being in need of structural case, have no trigger for scrambling out of the VP. ${ }^{9}$

Secondly, given that low functional projections have in general aspectual value, we would expect that these particles also do. As we will see below, this is not the case; on the contrary, the interpretation triggered by the presence of $S P s$ concerns semantic and pragmatic aspects such as presupposition, point of view, and presentation of the event, which are usually encoded in the left periphery of the clause.

Thirdly, the syntactic behaviour of $S P S$ suggests that they belong to the highest functional domain: as shown above, they are not found in embedded contexts: this asymmetry is a typical property of phenomena involving the $\mathrm{CP}$ field (like for example $V 2, d o$-support, subject clitic inversion, etc.); to the best of our knowledge, no elements of the low inflectional field are sensitive to the main versus embedded status of the clause in which they occur.

After claiming that $S P S$ are located in a head position of the CP layer and that their sentence final occurrence is derived via movement of their clausal complement, the whole CP, to their specifier, we intend to show now that the relation between $S P S$ and the preceding CP does indeed display the properties of the structural spec-head relation.

\footnotetext{
${ }^{9}$ Moreover, the structural position of the particle should be in that case the lowest specifier position above the VP projection: if it were a head, it would block verb movement and if it were not the lowest functional specifier, we would expect it to be followed by low adverbs.
} 
As is well known, parentheticals cannot intervene between a head and its specifier, while they can intervene between two maximal projections. ${ }^{10}$ Therefore, we can use parentheticals as a diagnostic test for spec-head relations; the following examples show that it is not possible to insert a parenthetical expression between the CP and any $S P$ :

(36) a. *L'à piovest, son sicur, lu, ieri sera it-has rained, I'm sure, lu, last night

b. *Cossa falo, diseme, ti? Ve what does-he, tell me, $t i$

c. *Vien, sa, mo! Ve come, you know, mo

Under the proposed analysis, the natural question arises as to whether all the particles are located in the same head or whether each particle occupies a different $\mathrm{C}^{\circ}$ position. As we will discuss in the next section, there are reasons to believe that each particle marks a different semantic value. ${ }^{11}$ There is, however, a more straightforward syntactic argument for the hypothesis that $S P S$ occupy different head positions inside the CP layer; interestingly, the particles $t i$ and $p o$ can cooccur, in a rigid order in which po precedes $t i$ :

(37) Quando eli rivadi, po, ti?

If the two particles cooccur, it is obvious that they cannot be located in the same head. According to our account there are two possible analyses of the sequence in (37), which can be derived either as in (38) or as in (39):

(38) a. [ [ti] [po] [cP quando eli rivadi]]

b. [ [ti $\left.]\left[[\mathrm{cP} \text { quando eli rivadi }]_{\mathrm{x}}[\mathrm{po}]\right] \mathrm{t}_{\mathrm{x}}\right]$

c. $\left.\left.\left.\left.\quad[\text { [ [[C quando eli rivadi }]_{\mathrm{x}}[\mathrm{po}]\right] \mathrm{t}_{\mathrm{x}}\right]_{\mathrm{y}}[\mathrm{ti}]\right] \mathrm{t}_{\mathrm{y}}\right]$

(39) a. [ [po] [ti] [cP quando eli rivadi]]

b. [ [po] [[cP quando eli rivadi $\left.\left.]_{\mathrm{x}}[\mathrm{ti}]\right] \mathrm{t}_{\mathrm{x}}\right]$

c. $\left.\left[[\text { cr quando eli rivadi }]_{\mathrm{x}}[\mathrm{po}]\right]\left[\mathrm{t}_{\mathrm{x}}[\mathrm{ti}]\right] \mathrm{t}_{\mathrm{x}}\right]$

As illustrated, we can hypothesize two different initial sequences, depending on the relative linear order of the two particles. If $t i$ is higher than $p o$, as in (38a), we have movement of the interrogative clause into the specifier of $p o$,

\footnotetext{
${ }^{10}$ The general constraint blocking the insertion of parenthetical elements, and of lexical material in general, between a head and its specifier, follows straightforwardly from the antisymmetric approach of Kayne 1994.

${ }^{11}$ Adopting Cinque's (1999) view that each functional projection can only encode one semantic feature, we are led to the conclusion that each particle occupies a different head position.
} 
as in (38b), and the final word order in (38c) is obtained by raising the whole constituent formed by the CP and the particle po into the specifier of $t i$. In the second derivation, with po higher than $t i$, as in (39a), the interrogative CP raises, through the specifier of $t i$, up to the specifier of $p o$. Beside the different initial order, the difference between the two alternatives lies in the second step of the derivation: only in the former case does the moved constituent include the lower particle. ${ }^{12}$

We have seen that some SPS can either be preceded by the whole interrogative clause, as in (40), or intervene between the sentence initial whitem and the rest of the clause, as in (41):

(40) a. Parché gnenlo, mo?

why comes-he, mo

b. Quando eli rivadi, po?

when have-they arrived, po

(41) a. Parché, mo, gnenlo?

why, mo, comes-he

b. Quando, po, eli rivadi?

when, po, have-they arrived

The examples in (40) show that the particle can be located in the left periphery, as it precedes the inflected verb which has undergone subject clitic inversion (we take subject clitic inversion to show that (some type of) verb movement to the CP layer has applied). ${ }^{13}$

12 On either analysis it is possible to account for the ungrammaticality of the following sequences:

(i) a. *Quando eli rivadi, ti, po?

b.??Po, quando eli rivadi, ti?

c.??Quando po éli rivadi ti?

[Po] when [po] have-they arrived [po/ti] [ti/po]

On the first analysis, the ungrammaticality of (ia) may be traced back to the fact that $t i$ requires its specifier position to be filled by the whole complement (including the particle $p o$ ); on the other hand, the deviance of (ib, ic) suggests that the raising of the whole clause to the specifier of $t i$ requires previous movement of the clause (and not only of the $w h$-item) to the specifier of $p o$, a condition which is virtually identical to the well known general restriction on successive cyclic movement according to which intermediate positions of the same type cannot be crossed over. On the other hand, the second analysis correctly predicts the ungrammaticality of (ia), where the particles are in the reverse order, as well as the deviance of (ib), where the specifier of po remains empty, and of (ic), where the wh-item has been extracted from a left branch.

${ }^{13}$ If we took (40) as the basic sequence, in view of (41) we would have to posit that the particle can either be merged in two different positions, belonging to very different sentence domains, or be merged very low in the structure and subsequently moved to the $\mathrm{CP}$ area for 
On our account, the particle occupies one and the same position, the difference between (40) and (41) depending on whether it attracts to its specifier the whole clause or only the $w h$-item, stranding the clause. Hence, cases like (41) are expected if we assume the analysis in (35) and have a structure like the following, where the element checking the strong feature in the specifier of the $S P$ is not the entire CP but the wh-item:

(42) $\left[\mathrm{FP} w h_{i}\left[\mathrm{~F}^{\circ}\right.\right.$ particle $\left.]\left[\mathrm{CP} \mathrm{t}_{i}\left[{ }_{\mathrm{IP}} \ldots \mathrm{t}_{\text {.... }}\right]\right]\right]$

We propose that the difference between particles that admit for this possibility and the ones that do not should be linked to the semantic feature the particle marks, as discussed below in detail. ${ }^{14}$

As for the obligatoriness of right dislocation in interrogative clauses, we assume that these cases should be treated along the lines of Kayne \& Pollock 2001 and Munaro, Poletto \& Pollock 2001, where it is proposed that these cases are to be analysed as left dislocation of the prosodically emarginated constituent to the specifier of a Topic projection, followed by remnant movement of the whole clause; according to our analysis, the XPs occurring after the particle are left dislocated to a $\mathrm{CP}$ position lower than the one occupied by the particle itself.

Empirical support for the idea that in the cases under examination what looks like right dislocation is left dislocation followed by clausal movement is provided by the contrasts in (43) and (44). As noted by Benincà (1988), right dislocation can be preceded by a focalized XP, which is prosodically tied to the verbal complex; interestingly, this does not hold for the kind of constructions we are examining here:

(43) a. *Vèrzila mo SUBITO, sta finestra Ve

b. Vèrzila mo, subito, sta finestra open-it [mo] soon [mo] this window

(44) a. *L'àtu vist mo IERI, to papà?

$\operatorname{Pg}$

b. L'àtu vist mo, ieri, to papà? him-have-you seen [mo] yesterday [mo] your father

In the examples (43b) and (44b) the adverb cannot be focalized, which shows that the object must have undergone left dislocation at some stage in the derivation.

some reason to be determined. This hypothesis is not plausible, given that $S P S$ do not encode any aspectual feature.

${ }^{14}$ A further argument in favour of our analysis is provided by the empirical generalization formulated above: those particles that can intervene between the $w h$-item and the rest of the clause may also occur with the $w h$-item in isolation. This fact follows straightforwardly from the analysis proposed here, while it would remain unaccounted for if we admitted that $S P S$ are located in the low IP area. 


\section{On the Interpretive Contribution of the Particles}

In this section we attempt a more thorough description of the contexts in which SPS are attested, thereby sketching an account of the semantic contribution of each particle to the interpretation of the clause.

\section{$5.1 \mathrm{Ti}$}

As already mentioned, $t i$ only appears in wh-questions and is not compatible with yes/no questions:

(45) a. Quando sarali rivadi, ti?

b. Sarali rivadi quando, ti? [when] be-fut-they arrived [when], $t i$

(46) a. *Saràli rivadi, ti? be-fut-they arrived, $t i$

b. *I ze partii, ti?

they-have left, $t i$

$T i$ questions can have two different interpretive shades and both correspond to non-canonical interpretations of the question. On the first interpretation, which can be identified with Obenauer's (1994) 'can't find the value' (henceforth $C f v$ ) reading, the speaker has already unsuccessfully tried to identify an appropriate value for the variable. ${ }^{15}$ The second interpretation is a surprise/reproach (henceforth $S r$ ) interpretation: in this case the speaker already knows the value of the variable, so his question does not really bear on the value of the variable bound by the wh-operator, but rather conveys a feeling of surprise or reproach towards the event referred to. ${ }^{16}$

We propose that the function of $t i$ is in both cases to signal that the value of the variable is outside the set of canonical answers. Suppose that the canonical way of interpreting a question is to present a class of possible answers and

${ }^{15}$ This type of question can only be a self-addressed question; interestingly, both in Venetian and in Pagotto (as exemplified in (ia) and (ib)), $t i$ cannot appear in epistemic questions, which display an overtly realized complementizer che and are generally in the subjunctive mood:

(i) a. Cossa che el gabia fato, (??ti)?

what that he-have-subj done (ti)

b. Che'l sia 'ndat andé, (??ti)?

that he-be-subj gone where (ti)

Questions of the type exemplified in (i) are also self-addressed questions, which might be taken to show that self-addressing in questions cuts across question types.

${ }^{16}$ For a more detailed analysis of questions with this particular type of pragmatic salience, the reader is referred to Poletto 2000: 67ff. and Munaro \& Obenauer 2002. 
invite the addressee to select one: $t i$ signals a non-canonical interpretation of the question, that is, the fact that the addressee is not allowed to choose a value for the variable from inside the set. So, the common feature shared by both the interpretations associated with the presence of $t i$ is the fact that the answer drawn from the set specified by the $w h$-item is not sufficient and/or relevant.

Let us analyse more in detail what semantic property these two interpretations share: in the $C f v$ interpretation all the possible values of the variable have already been tried and excluded by the speaker, while in the $\mathrm{Sr}$ interpretation the value of the variable is already identified but it is outside the set of plausible values defined by the context (see Obenauer 1994). Interestingly, the choice between the two interpretations seems to be connected to the verbal features, as present and past trigger the $\mathrm{Sr}$ interpretation more easily, while future favours the $C f v$ interpretation: ${ }^{17}$

(47) a. Dove le gavarò messe, ti?

$\mathrm{Ve}$ where cl have-fut-I put, $t i$

b. Cossa avarali magnà, ti? what have-fut-they eaten, $t i$

(48) a. Andé eli ndadi, ti? where have-they gone, $t i$

b. Cossa sì drio magnar, ti? Ve what are-you eating, $t i$

The choice is performed via different mood marking: both in $C f v$ questions and in $\mathrm{Sr}$ questions the activation of a modal feature may be involved, most likely an epistemic modality in the former case and an evaluative modality in the latter (see Munaro \& Obenauer 2002 for a specific proposal on the second type of questions). ${ }^{18}$

${ }^{17}$ Notice that $C f v$ questions with $t i$ are incompatible with second person subjects, which is probably due to the fact that the speaker excludes the possibility of receiving an answer from the addressee:

(i) a. *Andé sareo ndadi, ti?

b. *Dove sarì ndai, ti? where be-fut-you gone, $t i$

${ }^{18}$ That future tense can have modal properties is shown by examples like the following:

(i) Bussano alla porta. Sarà Gianni. (they) are knocking at the door. (It) will-be John 'Somebody is knocking at the door. Probably it's John.'

As illustrated by the English translation, the use of the future in this case triggers an epistemic interpretation. 
The fact that modality is relevant to the interpretation of the question could provide an explanation for why $t i$, unlike other particles, always requires the whole $\mathrm{CP}$, and not simply the $w h$-item, in its specifier. If the modal feature must be in a local structural relation with the particle, there are a priori two possible ways to satisfy this requirement: since $t i$ has no affixal properties, left-adjunction of the finite verb to the particle via head movement is excluded, so we are left with the option of pied-piping the whole CP up to the specifier of the particle. ${ }^{19}$

In the $S r$ interpretation not only does the speaker know that the value of the variable is outside the set; the set is defined either on the basis of acceptable values (producing the reproach reading) or on the basis of the expected values (producing the surprise interpretation). In other words the rough interpretation of (49a) is (49b):

(49) a. Cossa $\mathrm{C}_{\mathrm{C}}$ magnelo ti ?

b. \{magna cossa, $\mathrm{x}: \mathrm{x} \in \mathrm{C} \Delta \mathrm{x}$ is a thing

$\mathrm{C}=$ acceptable

$\mathrm{C}=$ expected

The two basic meanings of the $S r$ question type are thus derived from the typing of the set of possible values, which can be either expected or acceptable.

\subsection{Mo}

As anticipated above, the particle mo has a different distribution in Venetian and Pagotto, as only in the latter dialect can it occur both in interrogatives as well as in imperatives.

We propose that mo can have the following values in the structures examined: it introduces a presupposition and/or it expresses what has been described in the literature as a point of view. From these two properties we can derive its interpretive import in the two dialects under investigation. In Pagotto mo introduces 'point of view' because it expresses a reference to the person for whose benefit the action has to be performed (either the speaker or the hearer). Imperatives with mo are uttered to benefit a class of persons which includes the hearer (similar information is conveyed by the particles $\mathrm{mo} / \mathrm{ma}$ in the Rhaetoromance variety of Badiotto, as discussed in Poletto \& Zanuttini 2003):

\footnotetext{
${ }^{19}$ As for the fact that $t i$ occurs only in $w h$-interrogatives and not in yes/no questions, this may depend on the fact that in the latter the variable can have either a positive or a negative value; since these two values exhaust the set, there is no third value to be placed outside the set.
} 
(50) a. Magna, mo (che te deventa grant)!

eat, mo, (so that you grow up)

b. Ledelo, mo (che te capisarà tut)! read it, mo, (so that you'll understand everything)

(51) a. Nèteme le scarpe, mo (che sion in ritardo)! clean my shoes, mo, (that we are late)

b. Parèceme da magnar, mo (che dopo avon da 'ndar via)! cook for me, mo, (that later we have to go)

Sentences like the ones illustrated in (50) are clearly uttered to the advantage of the hearer, while those in (51) are felicitous only if they are uttered in a context in which both the speaker and the hearer benefit from the action performed. $^{20}$

As for the role of mo in imperatives in Venetian, it can be informally characterized as expressing the confirmation of an order already given, requiring that the action be performed immediately; as such it is not compatible with adverbs expressing future tense:

(52) a. Ciamime (*tra un'ora), mo!

$\mathrm{Ve}$ call me (in an hour), mo

b. Lezilo (*doman), mo! read it (tomorrow), mo

In Venetian imperatives $m o$ is sensitive to the tense of the utterance, as it signals that the utterance time and the performance time must coincide. In addition to this, mo signals the presence of a presupposition, that is, that the speaker already knows that the hearer does not intend to obey the order. The combination of these two factors, that is, the presupposition and the coincidence between utterance and performance time, yields a semantic effect characterized by Venetian informants as 'reinforcement of the order'.

In imperatives mo expresses two distinct values in the two dialects under investigation, but the reading conveyed by $m o$ in Pagotto interrogatives is partially similar to the one expressed in Venetian imperatives because in both cases a presupposition concerning the addressee's intentions is entailed (as noted above, mo does not appear in Venetian interrogatives). We surmise that

${ }^{20}$ The distinction concerning point of view attested in Pagotto is not relevant in Venetian, as mo can appear in the following imperative clauses, expressing an order whose performance is exclusively to the advantage either of the hearer or of the speaker:

(i) a. Vien mo, che te iuto! come mo, that I help you

b. Vien mo, che ti me porti casa! come mo, that you take me home 
in $m o$ interrogatives both a presupposition and a point of view are involved, the interpretation depending on the position of the $S P$ :

(53) a. Quando rivaràli, mo?

b. Quando, mo, rivaràli?

when $[\mathrm{mo}]$ arrive-fut-they [mo]

If the whole clause raises, as in (53a), the speaker expresses the fact that the present situation does not conform to his expectations, a fact which, due to the presence of the point of view, might have negative consequences; if point of view is encoded by a modal projection in the higher portion of IP (see Poletto \& Zanuttini 2003), then IP raising is necessary for the intended interpretation to obtain (as is the case with $t i$ ). When the particle occurs immediately after the $w h$-item, as in (53b) (or with the $w h$-item used in isolation), mo introduces the speaker's opinion that the addressee does not intend to answer, so that he is forced to repeat his question. Hence, what is expressed in this case is not a point of view, but just a presupposition; given the absence of point of view, the clause need not raise as a whole and the wh-item can, and must, raise alone. $^{21}$

We can conclude that both in Venetian imperatives and in Pagotto interrogatives (with the particle following the wh-item), the effect of reinforcement perceived by the informants is due to some presupposition concerning the addressee's attitude. How this presupposition is syntactically expressed, however, remains to be determined.

${ }^{21}$ A similar distinction between two different dialects is found the Rhaetoromance varieties spoken in the Badia valley; in the dialect spoken in S.Leonardo mo exclusively expresses the speaker's point of view:

(i) a. Arzignem mo le bagn

prepare-me mo the bath

b. *Töt mo n'de d vacanza

take mo a day of holiday

The ungrammaticality of (ib), which is uttered to the benefit of the addressee, shows that in this dialect the particle mo expresses an order to be performed to the benefit of the speaker. In the minimally different dialect of S.Vigilio di Marebbe mo encodes an order to be performed immediately and as such it is incompatible with adverbial forms of duration or referring to a point in the future:

(ii) a. Dayrela mo (*te siis mensc) open-it mo (*in six months)

b. Comportete mo (*entrees) bun behave-refl mo (*always) well 


\subsection{Po}

Also in the case of po the interpretation of the sentence depends on the position of the particle, which, as anticipated above, can appear either sentence-finally or immediately after the $w h$-item:

(54) a. Quando eli rivadi, po?

b. Quando, po, eli rivadi? when $[\mathrm{po}]$ have-they arrived $[\mathrm{po}]$

We claim that the contribution of $p o$ to the interpretation of the clause consists of two components: the fact that the set of the answers specified by the whitem is ordered according to a probability scale (along the lines of Portner \& Zanuttini's (1998) analysis of exclamative clauses) and that the most probable values have already been tried and excluded.

When po immediately follows the $w h$-item, as in (54b), the speaker knows that the event was supposed to take place and is asking for a confirmation; as discussed above for $m o$, this interpretation seems to convey a presupposition concerning the whole event, so that the question does not really bear on the wh-item. This position triggers an interpretation in which the possible values for the variable have been ordered according to a probability scale derived through the context, and the most probable ones have been excluded.

Sentence-final po, in (54a), in addition to the ordering of the possible values and the exclusion of the most probable ones, also entails the speaker's reference to a preceding communicative situation that has been left suspended and is taken up again at present. We suggest that the speaker's reference to a previous situation might be connected to the activation of the Tense projection, which, being relevant for this interpretation, must move to the specifier of the particle, pied-piping the whole clause (as in the cases of $t i$ and $m o$ ). ${ }^{22}$

${ }^{22}$ Indeed, this additional interpretation is excluded in Venetian with a future tense:

(i) \%Quando sarali rivai, po when be-fut-they arrived po

As mentioned above, in Pagotto po is also attested in sentence initial position, both in yes/no and in $w h$-questions:

(ii) a. Po, éli rivadi?

b. Po, quando éli rivadi?

po [when] are-they arrived

In both cases the presence of po conveys the speaker's mild surprise about the fact that the event has taken place, rather than focalizing the question on whether they have arrived or not or on the actual time of their arrival; hence the event is presented as unexpected given the context, and the value of the variable does not seem to be relevant. 


\section{$5.4 \mathrm{Lu}$}

The occurrence of the particle $l u$ is limited to non-constituent exclamatives presenting the whole propositional content as unexpected:

(55) a. L'é frét, lu

$\operatorname{Pg}$

it-is cold $[l u]$

b. L'é rivà al to amigo, lu it-has arrived your friend, lu

$\operatorname{Pg}$

So, in the two examples in (55) the speaker becomes aware of an unexpected matter of fact: in (55a) he realizes that the temperature is lower than he expected, while in $(55 \mathrm{~b})$ he is surprised about the fact that the addressee's friend is not going to arrive.

$L u$ is not compatible with constituent exclamatives in which a wh-phrase has been fronted to the sentence-initial position, as shown by the following examples:

(56) a. Che fret $(* 1 u)$ che l'é incoi (*lu) how cold $[l u]$ that it-is today $[l u]$

b. Quant (*lu) che l'à piovest ieri sera (*lu) how much $[l u]$ that it-has rained last night [lu]

We will limit ourselves to suggesting that the semantic function of $l u$ consists in introducing a presupposition. In this case, the event described by the clause corresponds to either of the two possible truth values (positive and negative); the propositional content expressed is contrary to the speaker's expectations, so the interpretive feature associated with $l u$ may be reduced to the choice of the contextually less probable value (between the two a priori conceivable ones).

In this respect the interpretive contribution of $l u$ in reversing the presupposition resembles the semantic function performed by mica in standard Italian (see Cinque 1976):

(57) Non fa mica freddo oggi not makes mica cold today

In (57) the speaker expresses the fact that, contrary to common expectations, it is not cold; in this sense, $l u$ could be viewed as the positive counterpart of mica.

\section{Summary}

In this article we have analysed the syntactic and semantic behaviour of some sentential particles attested in the Veneto dialects. The particles we have 
considered share some interesting properties: they are associated with specific clause types; they can only appear in matrix clauses; and they can all occur in sentence-final position and display the typical properties of $\mathrm{X}^{\circ}$-elements. Our hypothesis that each particle occupies a different head position within the CP layer is crucially supported by the possibility of combining two particles; however, their precise ordering and a precise characterization of the single projections they mark remains to be determined.

We have proposed a syntactic analysis exploiting movement of the $w h$-item or of the whole clausal complement to the specifier of the projection whose head is occupied by the particle. The interpretation triggered by the presence of the particle changes depending on whether the constituent which targets the specifier of the $S P$ is the $w h$-item or the whole clause. We have suggested that the raising of the whole CP-complement is induced by the necessity for some projection of the inflectional field (typically Tense or Mood) to enter a local structural relation with the particle; when this obtains Tense or Mood also contribute to the interpretation of the clause, which becomes a function of the semantic import of the particle combined with the interpretive contribution of the relevant projection. Each particle is sensitive to tense and modality features in a different way, an issue which deserves further investigation.

\section{References}

Antinucci, Francesco \& Guglielmo Cinque 1977. Sull'ordine delle parole in italiano: l'emarginazione, In Studi di grammatica italiana, vol. VI, pp. 121-146.

Benincà, Paola 1988. L'ordine degli elementi della frase e le costruzioni marcate in Lorenzo Renzi, Giampaolo Salvi, Anna Cardinaletti eds. Grande Grammatica Italiana di Consultazione. Il Mulino, Bologna, vol. 1, pp. 129-208.

Benincà, Paola 1996. La struttura della frase esclamativa alla luce del dialetto padovano In Paola Benincà et alii eds. Italiano e dialetti nel tempo. Saggi di grammatica per Giulio C.Lepschy. Bulzoni, Roma, pp. 23-43.

Cinque, Guglielmo 1976. Mica, In Annali della Facoltà di Lettere e Filosofia dell'Università di Padova, vol.1, pp. 101-112.

Cinque, Guglielmo 1999. Adverbs and Functional Heads. Oxford University Press, New York/Oxford.

Kayne, Richard 1994. The Antisymmetry of Syntax. MIT Press, Cambridge, MA.

Kayne, Richard \& Jean-Yves Pollock 2001. New Thoughts on Stylistic Inversion. In Aafke Hulk \& Jean Yves Pollock, eds., Subject Inversion and the Theory of Universal Grammar. Oxford University Press, New York/Oxford.

Munaro, Nicola 1997. Proprietà strutturali e distribuzionali dei sintagmi interrogativi in alcuni dialetti italiani settentrionali. Ph.D. diss., Universities of Padua/Venice.

Munaro, Nicola \& H.-G. Obenauer 2002. On the Semantic Widening of Underspecified Whelements In Manuel Leonetti, Olga Fernàndez Soriano \& Victoria Escandell Vidal, eds., Current Issues in Generative Grammar. Universidad de Alcalà/Universidad Nacional de Educacion a Distancia/Universidad Autònoma de Madrid, pp. 165-194. 
Munaro, Nicola \& Cecilia Poletto. 2002. Distribuzione ed uso delle particelle frasali in alcune varietà venete. Forthcoming In Quaderni Patavini di Linguistica 18. Unipress, Padua.

Munaro, Nicola \& Cecilia Poletto. Forthcoming. Ways of Clausal Typing, Rivista di Grammatica Generativa.

Munaro, Nicola, Cecilia Poletto \& Jean Yves Pollock. 2001. Eppur si muove! On Comparing French and Bellunese Wh-Movement. In Pierre Pica and Johan Rooryck, eds., Linguistic Variation Yearbook 1. John Benjamins, Amsterdam/Philadelphia, pp. 147-180

Obenauer, Hans-Georg 1994. Aspects de la syntaxe A-barre. Effets d'intervention et mouvements des quantifieurs. Thèse de doctorat d'état, Université de Paris VIII.

Pellegrini, Giovanbattista 1972. Saggi sul ladino dolomitico e sul friulano, Adriatica Editrice, Bari.

Poletto, Cecilia 2000. The Higher Functional Field, Oxford University Press, Oxford.

Poletto, Cecilia \& Raffaella Zanuttini 2003. Making Imperatives. In Christina Tortora, ed., The Syntax of Italian Dialects. Oxford University Press, Oxford/New York, pp.175-206

Portner, Paul \& Raffaella Zanuttini 1998. The Force of Negation in Wh-Interrogatives and Exclamatives, In Paola Benincà \& Cecilia Poletto eds. Quaderni di Lavoro dell'ASIS 2, CNR, Padova, pp. 13-37.

Rizzi, Luigi 1997. The Fine Structure of the Left Periphery In Liliane Haegeman, ed., Elements of Grammar, Kluwe, Dordrecht, pp. 281-337.

Rohlfs, Gerhard 1969. Grammatica storica della lingua italiana e dei suoi dialetti, vol. 3. Einaudi, Torino. 